\title{
The Antioxidant Activity of Recombinant Rat Hepatic Fatty Acid Binding Protein T94A Variant
}

Tyson Le ${ }^{1}$, Yuewen Gong ${ }^{1}$, Guqi Wang ${ }^{2,3}$, Neal M. Davies ${ }^{4}$, Ryan Lillico ${ }^{1}$, Ted Lakowski ${ }^{1}$, Michael S. Roberts ${ }^{5,6}$, and Frank J Burczynski ${ }^{1,7}$

${ }^{1}$ College of Pharmacy, Pharmaceutical Analysis Laboratory, Rady Faculty of Health Sciences, University of Manitoba, Winnipeg, MB, Canada. ${ }^{2}$ Department of Internal Medicine, Wake Forest University School of Medicine, Winston-Salem, NC 27157 USA. ${ }^{3}$ Whole Pharm Biotechnology Corp., Matthews, NC 28105 USA. ${ }^{4}$ Faculty of Pharmacy and Pharmaceutical Sciences, University of Alberta, Edmonton, AB, Canada. ${ }^{5}$ Diamantina Institute, University of Queensland, Translational Research Institute, QLD, 4102, Australia. ${ }^{6}$ School of Pharmacy and Medical Sciences, University of South Australia, Basil Hetzel Institute for Translational Medical Research, The Queen Elizabeth Hospital, Woodville South, Adelaide, South Australia 5011, Australia. ${ }^{7}$ Department of Pharmacology \& Therapeutics, Max Rady College of Medicine, Rady Faculty of Health Sciences, University of Manitoba, Winnipeg, MB, Canada.

Received, September 22, 2018; Accepted, November 1, 2018; Published, November 4, 2018.

ABSTRACT - PURPOSE: Liver fatty acid binding protein (FABP1) is a cytoplasmic polypeptide that transports substrates throughout the cytosol and functions as an antioxidant. A common polymorphic variant, FABP1 T94A has a minor allele frequency of $26-38 \%, 8.3 \pm 1.9 \%$ homozygous in the human population. The purpose of this study was to mutate and isolate recombinant rat FABP1 to the T94A variant to evaluate the mutant's antioxidant activity using in vitro studies. METHODS: Site-directed mutagenesis was used to generate a mutation in rat cDNA within a pGEX-6p-2 vector. This plasmid was transformed into competent cells and cultured for expression of FABP1 T94A mutant. The mutated protein was purified using GSTrap Fastflow columns within an ÄKTA FPLC system. A 2,7-dichlorofluorescein (DCF) assay was used to screen the T94A variant antioxidant activity. Additionally, Thiobarbituric Acid Reactive Substances (TBARS) assay was used in determining T94A mutant antioxidant activity in hydrophilic and lipophilic environments through the use of the azo compounds AAPH and MeO-AMVN, respectively and in the presence and absence of the long-chain fatty acid palmitate and $\alpha$-bromo palmitate. RESULTS: Although the FABP1 T94A $(20 \mu \mathrm{M})$ mutant significantly reduced DCF fluorescence compared to control (no protein; $\mathrm{P}<0.001$ ), there were no significant difference when compared to the wild-type (WT) FABP1. T94A was able to diminish the formation of malondialdehyde (MDA) in both lipophilic and hydrophilic systems. There were significant differences between T94A mutant and WT FABP1 at concentrations 1 and $10 \mu \mathrm{M}(\mathrm{P}<0.05)$ in the hydrophilic milieu, however, this was not seen at $20 \mu \mathrm{M}$ and also not seen in the lipophilic milieu at all concentrations. When T94A was pre-incubated with the long-chain fatty acids palmitate or $\alpha$-bromo palmitate, MDA formation was decreased in both lipid peroxidation systems. There were no statistical differences between the WT FABP1 and T94A bound with fatty acids in both lipid peroxidation systems, however, there was a slight statistical difference when the T94A and WT FABP1 bound $\alpha$-Br-PA in the AAPH lipid peroxidation system only. CONCLUSIONS: The T94A has antioxidant activity in both hydrophilic and lipophilic environments. The T94A variant of FABP1 does not have a loss of function in regard to acting as an antioxidant but the extent of function may be influenced by ligand binding. We conclude that populations having the minor T94A allele frequency would have similar ROS scavenging potential as those with nascent FABP1.

\section{INTRODUTION}

FABP1 is the intracellular equivalent to plasma albumin, binding lipophilic endogenous and exogenous compounds and transporting them throughout the cytosol. The protein is found in various tissues such as liver, intestine, pancreas, kidneys, lung, and stomach (0). FABP1 has been shown to be an effective intracellular antioxidant. A study showed the importance of FABP1 as an antioxidant utilized Chang cells, which are normally devoid of FABP1. Stably transfected cells with the FABP1 cDNA, showed lower concentrations of reactive oxygen species (ROS) than those without FABP1, suggesting that the protein can scavenge ROS (1).

Corresponding Author: F.J. Burczynski, College of Pharmacy, Rady Faculty of Health Sciences, University of Manitoba, 750 McDermot Ave. Winnipeg, Manitoba, Canada. frank.burczynski@umanitoba.ca 
It was further shown that FABP1 levels can be increased using clofibrate or decreased with dexamethasone, thus affecting ROS levels in models of $\mathrm{H}_{2} \mathrm{O}_{2}$ incubation or hypoxia-reoxygenation (2). FABP1 was shown to act as a potent hepatic antioxidant in animal models of cholestasis (3), alcohol liver disease (4), acetaminophen toxicity (5), in in vitro models of NAFLD (6). FABP1 may thus play a critical role in oxidative homeostasis within the liver. The molecular mechanism for FABP1's antioxidant function was reported to centre on the solvent accessible methionines (five out of seven) and single cysteine being responsible for scavenging ROS (7). Others have subsequently reported the antioxidant role of FABP in other species $(8,9)$. Reports showed that when liver damage was induced by environmental stress on orange-spotted groupers, FABP10 (a paralog of FABP1) acts as an antioxidant (8). Decreased expression of FABP1 in zebrafish larvae also was associated with lower superoxide dismutase activity and higher levels of malondialdehyde (MDA) (9).

FABP1 T94A is a missense mutation in the human Fabpl gene where the $94^{\text {th }}$ amino acid, a polar moderate sized threonine, is substituted for a non-polar, small sized alanine residue (11). The single nucleotide polymorphism (SNP) is considered common within humans having a minor allele frequency of $26-38 \%$; $8.3 \%$ homozygous MAF for 1000 genomes in NCBI dbSNP database; ALFRED database (11). Carriers are associated with higher triacylglycerol, elevated free fatty acid in plasma, and lower body mass index (11). Moreover, the mutant variant is linked with atherothrombotic cerebral infarction (12) and non-alcoholic liver disease (13). Initially, the T94A substitution was thought to completely abolish the binding and function properties of the protein. Recent studies revealed the substitution did not alter ligand binding affinity, however, it significantly altered conformational and functional response to fibrates as well as stability (14). The altered function was also demonstrated with fatty acids and triglyceride intermediates (15). The FABP1 T94A variant also has an increased affinity for cholesterol that may be due to a change in the binding site's polarity (16).

Since it has been established that FABP1 acts as a critical antioxidant in the liver and that the T94A variant is associated with altered functional response to drug binding, determining whether the T94A variant would be associated with impaired antioxidant function is important and has yet to be elucidated. As FABP1 accounts for about $2 \%$ of total cytosolic protein (17), the loss of the protein's antioxidant ability would compromise carriers during states of oxidative stress. Therefore, the current study aims in determining the antioxidant ability of FABP1 T94A using in vitro assays.

\section{METHODS}

\section{Materials}

Triton X-100, phenylmethylsulfonyl (PMSF), aprotinin, leupeptin, reduced glutathione, dithiothreitol (DTT), 2, 7-dichlorofluoresceindiacetate (DCFH-DA), hydrogen peroxide $\left(\mathrm{H}_{2} \mathrm{O}_{2}\right)$, low density lipoproteins (LDL), palmitate (PA), alpha-bromo palmitate $(\alpha-\mathrm{Br}-\mathrm{PA})$, and $\mathrm{DH} 5 \alpha-\mathrm{T} 1^{\mathrm{R}}$ competent cells were purchased from Sigma (St. Louis, MO, USA). Site-Directed Mutagenesis system kit, LB broth, and isopropyl- $\beta$-D-thiogalactoside (IPTG), were purchased from Fisher Scientific (Ottawa, ON, CA). Mutagenic primers, pGEX 3' Sequencing Primer, 5', GSTrap Fastflow columns, and PreScission Protease were obtained GE Life Sciences, Chicago, USA). Thiobarbituric acid (TBA) was purchased from EMD Millipore (Billerica, MA, USA). 2, 2'-Azobis (2methylpropionamidine) dihydrochloride (AAPH) and 2,2'-Azobis(4-methoxy-2,4dimethylvaleronitrile) (MeO-AMVN) were purchased from Wako (Osaka, Japan).

\section{Site-Directed Mutagenesis, Expression and Purification of Recombinant FABP1 and T94A}

The introduction of the T94A mutation to the pGEX6P-2 vector containing rat FABP1 cDNA was accomplished using the GENEART Site-Directed Mutagenesis System (Invitrogen, ThermoFisher Scientific, Mississauga, Canada) $(18,19)$. The pGEX-6P-2 vector containing rat FABP1 cDNA was previously constructed (7), sequences for mutagenic primers were ${ }^{5}$ AAT AAA ATG GTG ACA GCT TTC AAA GGC ATA A ${ }^{3}$ and ${ }^{5}$ T TAT GCC TTT GA A AGC TGT CAC CAT TTT ATT ${ }^{3}$.

pGEX-6P-2 with the FABP1 T94A mutant or wild-type (WT) FABP1 were transformed in E. coli DH5 $\alpha$ cells for large scale production of the FABP1 T94A variant and WT FABP1 control. For each construct, a single colony from a freshly streaked plate was used to inoculated $3 \mathrm{~mL}$ LB with 100 $\mu \mathrm{g} / \mathrm{mL}$ ampicillin and $20 \mathrm{mM}$ dextrose as a starter culture and grown overnight by shaking (200 rpm) at $37^{\circ} \mathrm{C}$. Each was then diluted into $500 \mathrm{~mL} \mathrm{LB}$ broth 
in 2.8 L Fernbach flask and incubated for 5-6 hours at $37^{\circ} \mathrm{C}$ with $200 \mathrm{rpm}$ until an OD600 $\approx 1.0$ was reached. FABP1 T94A expression was induced with the addition of $1 \mathrm{mM}$ of isopropyl- $\beta$-D-thiogalactoside (IPTG) for six hours at $37^{\circ} \mathrm{C}$. Cells were collected by centrifugation at $3500 \mathrm{~g}$ for 20 minutes, and resuspended in $20 \mathrm{~mL}$ of ice-cold 1 X PBS containing 1\% Triton X-100 and protease inhibitors (PMSF, aprotinin, and leupeptin at concentrations of $25 \mu \mathrm{g} / \mathrm{ml}, 2 \mu \mathrm{g} / \mathrm{ml}, 1 \mu \mathrm{g} / \mathrm{ml}$, respectively). Cells were then sonicated on ice for five cycles of 30 seconds with 30 seconds rest using a Branson Sonifier 450 (Danburry, Connecticut, USA) and centrifuged at $14,000 \mathrm{~g}$ for 15 minutes at $4^{\circ} \mathrm{C}$. WT FABP 1 and the T94A variant were purified from the cell lysate using the ÄKTA Fast protein liquid chromatography (FPLC) and GSTrap FF columns using the elution buffer $(50 \mathrm{mM}$ Tris- $\mathrm{HCl}, 10 \mathrm{mM}$ reduced glutathione, $1 \mathrm{mM}$ DTT, $\mathrm{pH}$ 8.0). Eluted protein sample was cleaved with the addition of $500 \mu \mathrm{L}$ PreScission Protease $(40 \mu \mathrm{L}$ PreScission Protease and $460 \mu \mathrm{l}$ of cleavage buffer [ $50 \mathrm{mM}$ Tris- $\mathrm{HCl}, 150$ $\mathrm{mM} \mathrm{NaCl}, 1 \mathrm{mM}$ EDTA, $1 \mathrm{mM}$ dithiothreitol (DTT), $\mathrm{pH}$ 7.5]). The pGEX-6P-2 has a cleavage site for PreScisson Protease to cleave the protein of interest from the GST tag leaving an N-terminal infusion linker, sequence of GPLGSIAT. The eluted fusion protein was incubated with protease at $4^{\circ} \mathrm{C}$ overnight with end over end rotation. After digestion, the FABP1 or T94A variant samples were re-added to an equilibrated GSTrap FF column, collected and concentrated using Amicon Ultra-15 Centrifugal Filter Devices with centrifugation at 5,000 g for 60 minutes. To validate DNA sequencing (FABP1 and T94A), the DNA plasmid was sent to the Manitoba Institute of Cell Biology for DNA sequencing using pGEX 3' Sequencing Primer, 5'.

\section{Sodium Dodecyl Sulfate Polyacrylamide Gel Electrophoresis (SDS-PAGE)}

SDS-PAGE was performed to identity the purified recombinant protein. A $15 \%$ separating and 5\% stacking gel were used for the SDS-PAGE and Western blot. Composition of the separating gel was $2.3 \mathrm{~mL}$ double distilled water, $2.5 \mathrm{~mL}$ Tris- $\mathrm{HCl}$ (1.5M), $100 \mu \mathrm{L}$ SDS (10\%), $2.5 \mathrm{~mL}$ acrylamide mix (30\%), $100 \mu \mathrm{L}$ ammonium persulfate (APS) (10\%), and $4 \mu \mathrm{L}$ tetramethylethylenediamine (TEMED). Compostition of stacking gel was $3.4 \mathrm{~mL}$ double distilled water, $0.63 \mathrm{~mL}$ Tris- $\mathrm{HCl}(1 \mathrm{M}), 50 \mu \mathrm{L}$ SDS (10\%), $0.83 \mathrm{~mL}$ acrylamide mix (30\%), $50 \mu \mathrm{L}$ APS (10\%), and $5 \mu \mathrm{L}$ TEMED . Running buffer consisted of $25 \mathrm{mM}$ Tris, $190 \mathrm{mM}$ glycine, $0.1 \%$ SDS (250 $\mathrm{mL})$. A total of $30 \mu \mathrm{g}$ protein $(15 \mu \mathrm{L})$ was added to $(5 \mu \mathrm{L}) 4 \mathrm{x}$ sample loading buffer $(250 \mathrm{mM}$ Tris- $\mathrm{HCl}$ pH6.8, 20\% glycerol $8 \%$, sodium dodecyl sulfate (SDS), $0.2 \%$ bromophenol blue, and $5 \% \quad \beta$ mercaptoethanol). Samples were boiled for 5 minutes at $100^{\circ} \mathrm{C}$ and briefly centrifuged using a Mini Centrifuge (Mandel Scientific, Ontario, Canada). Samples $(20 \mu \mathrm{L})$ were loaded into the wells. Electrophoresis was performed at a constant 100 Volts for 90 minutes using the Miniprotean II cell powered by Powerpac 1000 (Bio-Rad, Hercules, USA) afterwhich gels were rinsed with water (3X) before being stained with Coomassie $(0.1 \%$ Coomassie R-250, 10\% acetic acid, 40\% methanol). Bands were viewed following destaining.

\section{Western blot}

Identity of proteins was confirmed by Western blot analysis. Proteins separated by SDS-polyacrylamide gel were transferred to $0.45 \mu \mathrm{m}$ nitrocellulose membranes and blot run for $1 \mathrm{hr}$ at $100 \mathrm{~V}$. Membranes were rinsed in water $(3 x)$ before being blocked with $5 \%(\mathrm{w} / \mathrm{v})$ non-fat skim milk in Tris buffered saline with Tween 20 (TBST) solution (20 $\mathrm{mM}$ Tris pH 7.5, $150 \mathrm{mM} \mathrm{NaCl}, 0.1 \%$ Tween 20) for 1 hour at RT with gentle agitation. Membranes were then washed (3x) with $30 \mathrm{~mL} 1 \mathrm{X}$ TBST for 5 minutes and then incubated with $10 \mathrm{~mL}$ rabbit polyclonal LFABP antibody (Santa Cruz Biotechnology, Dallas, USA) (1:500 in 5\% powdered non-fat skimmed milk in TBST) overnight with gentle agitation. After the application of the primary antibody, membranes were washed $(5 \mathrm{x})$ with $30 \mathrm{~mL}$ of $1 \mathrm{X}$ TBST for 5 minutes each and incubated with goat anti-rabbit IgG-horseradish peroxidase (Santa Cruz Biotechnology, Dallas, USA) (1:500 in TBST) for 1 hour at RT with gentle agitation. After incubation membranes were washed (5x) with $30 \mathrm{~mL}$ TBST for 5 minutes each. Samples in the membrane were detected by enhanced chemiluminescence using the ECL Plus system from GE Lifesciences. Protein samples were also sent to the Pharmaceutical Analysis Laboratory at the University of Manitoba to confirm protein size by LC-MS.

\section{Ultra-High Performance Liquid Chromatography Mass Spectrometry (UHPLC- MS) Assay}

Mass spectrometry was performed using a Shimadzu LCMS-8040 triple-quadrupole mass spectrometer; LC-MS/MS (Shimadzu, Kyoto, Japan) 
coupled to a Nexera ultra high performance liquid chromatograph (Shimadzu, Kyoto, Japan) and analyzed using Shimadzu LabSolutions software. The MS was operated in DUIS mode (ESI/APCI) using a positive scan between 1000 and $2000 \mathrm{~m} / \mathrm{z}$. MS conditions consisted of a desolvation line temperature of $250^{\circ} \mathrm{C}$ and heating block temperature of $400{ }^{\circ} \mathrm{C}$. Nebulizing gas flow was $2 \mathrm{~L} / \mathrm{min}$ and drying gas was $15 \mathrm{~L} / \mathrm{min}$. FABP1 and the T94A variant were analzed on a Waters Aquity UPLC BEH $\mathrm{C} 18$ column $(1.7 \mu \mathrm{m}, 2.1 \times 100 \mathrm{~mm})$ at $40^{\circ} \mathrm{C}$ using a binary gradient of mobile phase A (aqueous $0.1 \%$ trifluoro acetic acid, TFA) and mobile phase B (methanol with $0.1 \%$ TFA) with a total flow rate of $0.3 \mathrm{~mL} / \mathrm{min} .10 \%$ mobile phase B was held for $1 \mathrm{~min}$ followed by a $2 \mathrm{~min}$ gradient to $80 \% \mathrm{~B}$, which was held for $12 \mathrm{~min}$. The column was washed with $90 \%$ B for $5 \mathrm{~min}$ and stepped back to $10 \%$ B for $5 \mathrm{~min}$ to recondition the column. The retention time of WT FABP1 and T94A was 5.8 minutes. The mass spectra extracted from each chromatogram was deconvoluted using the Multi-Charded Ion Analysis to report mass.

\section{DCF (2,7-dichlorofluorescein) Fluorescence Assay}

A DCF assay was used in determining whether the FABP1 T94A variant possessed antioxidant capacity similar to that of the WT FABP1. Briefly, 2,7dichlorofluorescein-diacetate (DCFH-DA) was deesterified by reacting with ethanol and sodium hydroxide yielding 2,7-dichlorodihydrofluorescein $(\mathrm{DCFH})$. This non-fluorescent derivative was the dye stock solution prepared daily. DCFH when oxidized by ROS produces the fluorescent compound DCF. Oxidation reactions were performed in 96 well CoStar plates where $50 \mu \mathrm{L}$ of different concentrations of protein sample or control were added to $40 \mu \mathrm{L}$ DCFH [60 $\mu \mathrm{M}], 5 \mu \mathrm{L}$ iron (II) sulfate $\left(\mathrm{FeSO}_{4}\right)[1 \mathrm{mM}]$, and $5 \mu \mathrm{L}$ hydrogen peroxide $\left(\mathrm{H}_{2} \mathrm{O}_{2}\right)[1 \mathrm{mM}]$. Sample fluorescence was read using a Synergy HT BioTeK microplate reader (Winooski, Vermont, USA) at $485 \mathrm{~nm}$ excitation and $590 \mathrm{~nm}$ emission.

\section{TBARS Assay}

Lipid peroxidation was assessed by investigating the presence of lipid peroxides that decompose into reactive malondialdehyde (MDA) compounds. LDL provides a platform for the free radicals to attack, resulting in lipid peroxides such as MDA. Lipid peroxidation products are highly reactive forming adducts with biologically important macromolecules. Hence, the TBARS assay illustrates the capacity of a protein to act as an antioxidant. Lipid peroxides are generated by incubating LDL with the azo compounds 2, 2'-azobis (2-methylpropionamidine) dihydrochloride (AAPH) or 2, 2'-azobis(4-methoxy-2,4-dimethylvaleronitrile) (MeO-AMVN). These azo compounds thermally decompose into free radicals in hydrophilic and lipophilic environments, respectively. Malondialdehyde bis (dimethyl acetal 1, 1, 3, 3tetramethoxypropane) was prepared fresh and used as a standard. LDL $[0.5 \mathrm{mg} / \mathrm{mL}]$ was incubated with either AAPH [10 mM] or MeO-AMVN [1 mM] and varying concentrations of protein in a $37^{\circ} \mathrm{C}$ water bath for 90 minutes. The addition of a TBA solution $(0.67 \%$ TBA, $15 \%$ trichloroacetic acid, $0.25 \mathrm{~N} \mathrm{HCl})$ halts the oxidation reaction. Samples were then heated at $100^{\circ} \mathrm{C}$ for 15 minutes to develop the colorimetric pink chromogen. Reactions were then cooled on ice for 5 minutes and centrifuged briefly to pellet the flocculates with the supernatant absorbance being analyzed at $535 \mathrm{~nm}$. The TBARS assay was also used to evaluate whether proteins were affected by binding with the long-chain fatty acids palmitate and $\alpha$-bromo palmitate, in which case $10 \mu \mathrm{M}$ of the proteins were pre-incubated with the fatty acids $(30 \mu \mathrm{M})$ for 1 hour before being subjected to oxidation reactions.

\section{STATISTICAL ANALYSIS}

Data are presented as mean \pm SEM. The $\mathrm{N}$ value represents the number of replicates for each study. Statistical analysis used t-test (unpaired) where two groups were compared while a two-way ANOVA was employed for multiple comparisons followed by a Bonferroni post-test using GraphPad Prism 6.0. Results were considered significant when the pvalue was less than 0.05 .

\section{RESULTS}

Identification of the Plasmid Vector pGEX-6P-2 with FABP1 cDNA by Restriction Enzyme Mapping

FABP1 cDNA was initially ligated into the pGEX6P-2 vector with BamHI and XhoI restriction enzyme recognition sequences (8). By using these endonucleases the isolated plasmid was cleaved into the vector and the cDNA permitting the separation of the DNA into bands of appropriate sizes with agarose 
gel electrophoresis. Separation between the plasmid vector at an estimated $4900 \mathrm{bp}$ and the FABP1 cDNA at 418 bp is shown in Figure 1. Figure 1 also shows that there was no difference between the original and mutated pGEX-6P-2 and FABP1/T94A bands, suggesting no unnecessary deletions or insertions occurred during site directed mutagenesis.

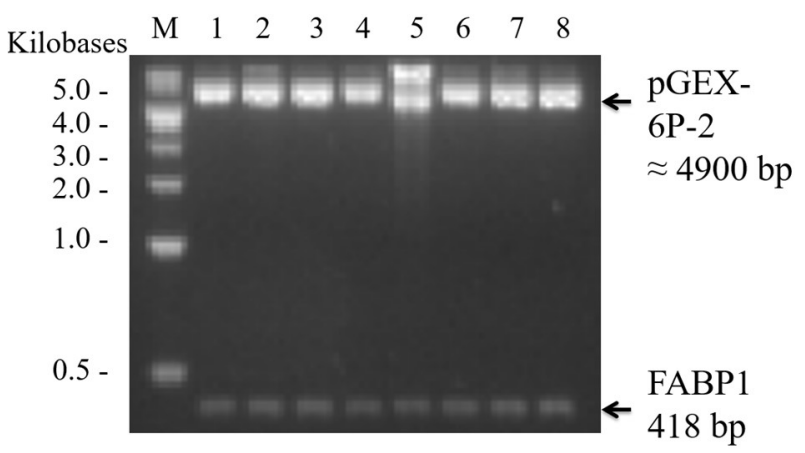

Figure 1. Analysis of recombinant pGEX-6P-2/FABP1 using restriction enzyme mapping after site-directed mutagenesis using GENEART Site Directed Mutagenesis System. Plasmids were purified using the plasmid midi kit from QIAGEN and digested with endonucleases at $37^{\circ} \mathrm{C}$ for 4 hours. DNA samples were loaded into $1.0 \%$ agarose gel and ran for 90 minutes at $100 \mathrm{~V}$. The gel was stained with SYBR Safe and visualized with a UV transilluminator. Lanes 1 and 2 show the original plasmid

\section{A}

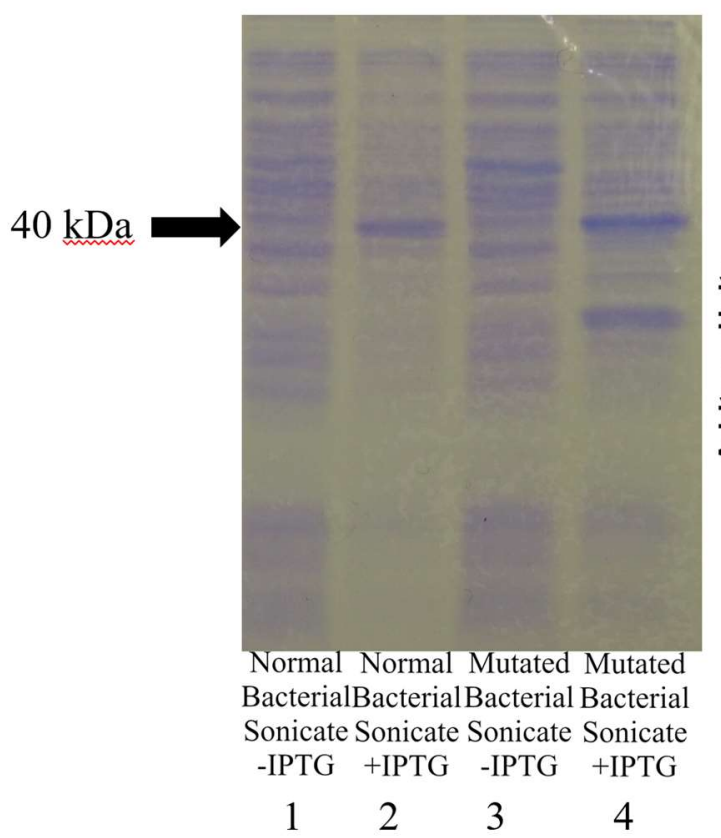

while the mutated plasmid digested with BamH1 and Xho1 are in lanes 3-8 pGEX-6P-2/FABP1.

\section{Expressing Recombinant proteins FABP1 and the FABP1 T94A Mutant Variant}

Plasmids used in this study contained FABP 1 and the mutated variant T94A cDNA fragments. Fragments were located between restriction enzymes site BamHI and XhoI, which is downstream of the GST tag sequence. The promoter for the GST tag was induced by introducing $1 \mathrm{mM}$ IPTG to the bacterial culture and incubated for an additional 6 hours before collecting cells. Figure 2A shows results from the $15 \%$ SDS-PAGE gel comparing non-mutated and mutated bacterial sonicates with and without bacterial induction with IPTG. The dark band indicated by the arrow at $40 \mathrm{kDa}$ shows the fusion protein FABP1 or T94A with the GST tag. Lanes 2 and 4 show incubation with IPTG resulting in darker bands than those in lanes 1 and 3. Figure 2B illustrates a histogram of band density of the gel seen in Figure 2A using ImageJ for analysis. From Figure 2B, samples that were induced with IPTG have clearly stronger band densities compared to samples that were not induced by IPTG.

\section{$\mathrm{B}$}

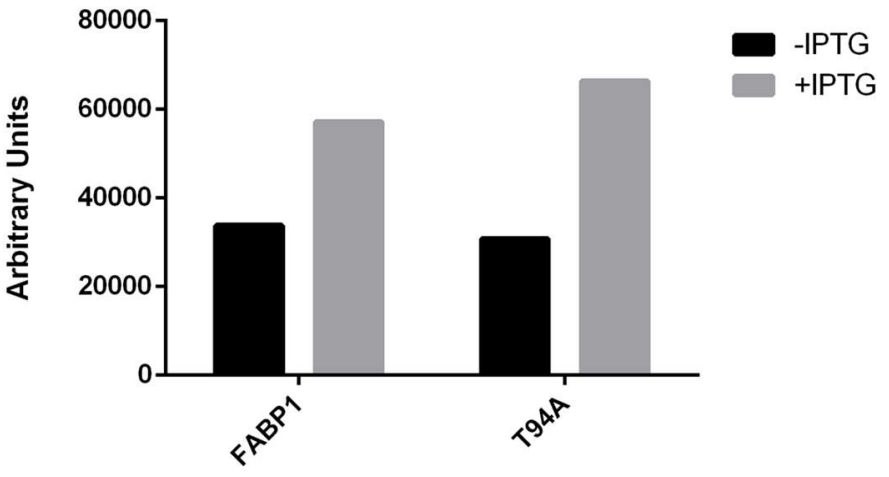

Figure 2. Protein induction with IPTG. The single experiment illustrates the use of IPTG to induce protein expression. (A) $15 \%$ Tri-Glycine SDS-PAGE gel. From left to right: Normal bacterial sonicate (1), induced normal bacterial sonicate (2), mutated bacterial sonicate (3), induced bacterial sonicate (4). (B) Histogram illustrating the band density from the $15 \%$ TriGlycine SDS-PAGE gel of Figure 2A between IPTG induced and uninduced bacterial cultures. 


\section{The Purification of Recombinant FABP1 and FABP1 T94A}

The fusion protein was purified and the GST tag separated from FABP1 or T94A variant with PreScission protease. Figure 3 shows a $15 \%$ polyacrylamide gel loaded with Amercham $^{\mathrm{TM}}$ ECL $^{\mathrm{TM}}$ Rainbow ${ }^{\mathrm{TM}}$ Marker- Full Range, normal bacterial sonicate, induced normal bacterial sonicate, mutated bacterial sonicate, induced mutated bacterial sonicate, normal fusion protein, mutated fusion protein, WT FABP1, and the T94A variant protein. Figure 3A, lanes 6 and 7 show both the WT and mutated fusion proteins having a molecular mass of $40 \mathrm{kDa}$, which is consistent with FABP1 or its T94A mutant $(14 \mathrm{kDa})$ and the GST tag $(26 \mathrm{kDa})$. The next two lanes show purified recombinant proteins at $14 \mathrm{kDa}$ after cleavage and additional purification to remove the tag and protease. The last four lanes show no contaminants present despite loading up to $30 \mu \mathrm{g}$ of protein in each well. To further confirm identities of the purified proteins a western blot was conducted. Figure $3 \mathrm{~B}$ shows the western blot of the purified recombinant proteins. The result shows that the recombinant protein samples are immunoreactive with the rabbit polyclonal antibody against rat FABP1. A second method of identifing purified proteins used LC-MS in determining the proteins' mass. Figure 4 is the total ion count chromatogram and the deconvoluted mass of FABP1 (A) and T94A (B). The deconvoluted mass of FABP1 was $1468 \mathrm{Da}$ and the T94A was $1438 \mathrm{Da}$ showing a difference of $30 \mathrm{Da}$, corresponding to the difference in mass between threonine and alanine.

B

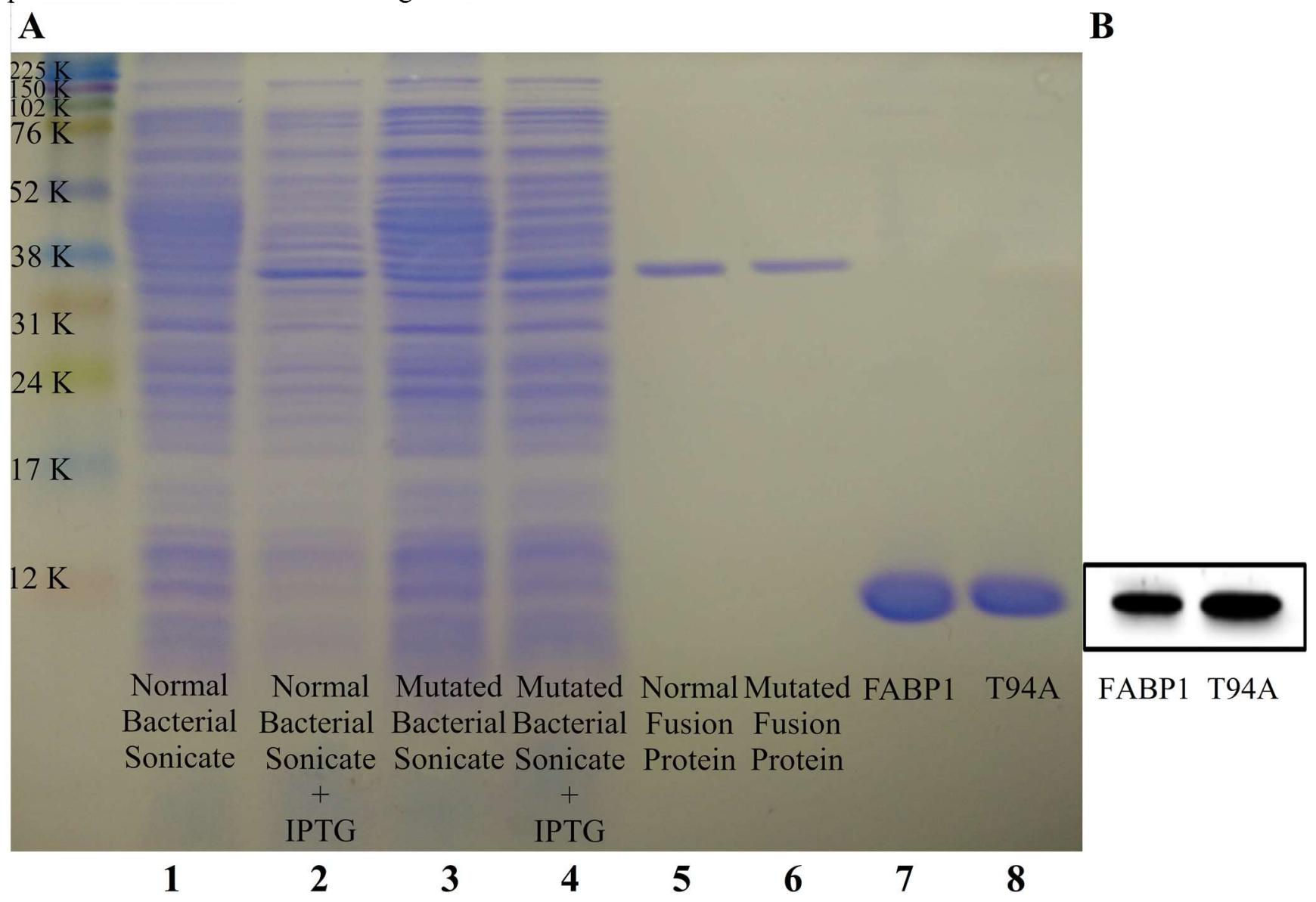

Figure 3. Identification of Proteins using SDS-PAGE (A) and Western Blot (B) using 15\% Tri-Glycine SDS-PAGE gel. From left to right: Amercham ${ }^{\mathrm{TM}} \mathrm{ECL}^{\mathrm{TM}}$ Rainbow ${ }^{\mathrm{TM}}$ Marker- Full Range, normal bacterial sonicate (lane 1), induced normal bacterial sonicate (lane 2), mutated bacterial sonicate (lane 3), induced mutated bacterial sonicate (lane 4), normal fusion protein (lane 5), mutated fusion protein (lane 6), FABP1 (lane 7), and the T94A variant protein (lane 8). B) Western Blot of the WT FABP1 and T94A variant proteins. Lanes 5 and 6 indicate the non-mutated WT and mutated fusion proteins have a molecular mass of $40 \mathrm{kDa}$, from FABP1 or its mutant $(14 \mathrm{kDa})$ and the GST tag $(26 \mathrm{kDa})$. Lanes 7 and 8 are purified recombinant proteins at $14 \mathrm{kDa}$ after cleavage and additional purification to remove the GST tag and protease. 


\section{Antioxidant Capacity of Recombinant FABP1 T94A}

One of the main objectives of this study was determining whether recombinant rat FABP1 T94A variant possesses the ability to act as an antioxidant similar to its non-mutated WT form. To evaluate the protein's antioxidant capacity, DCF fluorescence assay was employed using ascorbic acid and TROLOX ${ }^{\mathrm{TM}}$ as controls. Figure 5 shows that at the lowest concentration of T94A $(1 \mu \mathrm{M})$, the protein was able to reduce DCF fluorescence to $75.8 \pm 2.9 \%$, compared to control $(0 \mu \mathrm{M})$ while at its highest tested concentration of $20 \mu \mathrm{M}$ a reduction to $36.3 \pm 2.2 \%$ of control was seen $(\mathrm{P}<0.001)$. There was a dose response relationship between increasing concentration of T94A mutant and decreasing DCF fluorescence, suggesting that the protein functions as an antioxidant. When comparing T94A mutant to WT FABP1, there were no significant differences in their ability to reduce DCF fluorescence at all concentrations, suggesting that the T94A mutation does not significantly affect the ROS scavenging properties of FABP1.

\section{Effect of Recombinant FABP1 T94A on in vitro Lipid Peroxidation with AAPH and MeO-AMVN} To further evaluate the antioxidant activity of FABP1 T94A, AAPH and MeO-AMVN were used to release free radicals in the presence of LDL in hydrophilic or lipophilic environments, respectively. Since these compounds thermally decompose at different rates it was necessary to standardize their concentrations such that free radical release would be similar. Using a TBARS assay, LDL was incubated with $10 \mathrm{mM}$ AAPH and found to produce $670.1 \pm 13.4 \mathrm{ng}$ MDA/ mg LDL protein, which was not statitiscally different than MeO-AMVN at $1 \mathrm{mM}$ generating 713.0 $\pm 11.2 \mathrm{ng} \mathrm{MDA} / \mathrm{mg}$ LDL protein. Since these concentrations of azo compounds produced similar amounts of MDA they were used in determining T94A's antioxidant activity in hydrophilic and lipophilic environments. FABP1 was reported to have more activity in the hydrophilic environment (8), it is of interest and importance in determining whether the T94A mutation has similar activity. Figure $6 \mathrm{~A}$ shows that at a concentration of $20 \mu \mathrm{M}$, T94A produced $72.1 \pm 4.4 \%$ of control MDA formation in the hydrophilic system. In the lipophilic system, the T94A protein was able to inhibit $23.4 \pm 5.5 \%$ of MDA from forming at $20 \mu \mathrm{M}$ (Figure $6 \mathrm{~B})$. The variant was able to reduce MDA in a dosedependent manner in both environments (Figure 6A and B), suggesting the mutant can act as an antioxidant in both systems. Positive controls used for the assay included ascorbic acid and TROLOX ${ }^{\mathrm{TM}}$ in the AAPH system while in the MeO-AMVN system ascorbic acid acted as a negative control. When comparing FABP1 WT to T94A with AAPH being used as a source of ROS, there was a significant difference between proteins at concentrations at $1 \mu \mathrm{M}(79.8 \% \pm 1.5$ and $105.0 \% \pm 9.4$ of the WT control) and $10 \mu \mathrm{M}(65.8 \% \pm 1.8$ and $88.1 \% \pm 5.7$ of WT control) only $(\mathrm{P}<0.05)$. When antioxidant activities of FABP1 and T94A were used in a lipophilic environment with MeO-AMVN, there was no statistical difference in MDA production (Figure 6B). Figure 7 shows a summary of the WT FABP1 and T94A data using AAPH and MeOAMVN systems.

\section{Influence of Long-Chain Fatty Acid Binding on FABP1 T94A's Antioxidant Function}

Some of the FABP1 antioxidant residues are contained within its binding pocket. Consequently, binding with ligands may affect the protein's ability to act as an antioxidant (8). Previous work shows that FABP1 has very good antioxidant activity when the protein is in the unbound state but in the presence of fatty acids its activity is reduced (8). In this study we investigated whether FABP1 T94A's function as an antioxidant also could be influenced by binding fatty acids. In determining the effects of fatty acid binding, we pre-incubated purified recombinant proteins $(10 \mu \mathrm{M})$ with either $30 \mu \mathrm{M}$ of palmitic acid (PA) or $\alpha$-bomo palmitate ( $\alpha$-Br-PA). Palmitic acid binds reversibly to FABP1 while $\alpha$-bomo palmitate effectively binds irreversibly to FABP1. Figure 8A shows MDA production with unbound recombinant proteins while Figures $8 \mathrm{~B}$ and $\mathrm{C}$ show proteins bound with palmitic acid and $\alpha$-bomo palmitate, respectively.

In the AAPH environment, unbound WT FABP1 and T94A had statistically lower amounts of MDA produced compared to control (Figure 8A). Unbound WT FABP1 and T94A were associated with MDA production of $61.1 \pm 1.8 \%$ of control $(p<0.001)$ and $83.2 \pm 6.1 \%$ of control $(\mathrm{p}<0.05)$, resepctively, which were also statistically different from each other $(\mathrm{p}<0.01)$. In the MeO-AMVN environment, unbound WT FABP1 and T94A had statistically lower amounts of MDA produced compared to control (Figure 8A). Unbound WT FABP1 and T94A were associated with MDA production of $75.4 \pm 6.3 \%$ of control $(\mathrm{p}<0.01)$ and $83.4 \pm 5.9 \%$ of 
control $(p<0.05)$, which were not statistically different from each other.

When WT FABP1 and T94 were bound to PA both proteins showed statistical differences from control (Figure 8B). In the AAPH environment, WT FABP1 was associated with MDA production of $79.8 \pm 3.7(\mathrm{p}<0.001)$ while T94A had $87.6 \pm 2.5 \%$ of control $(\mathrm{p}<0.01)$. There was no statistical difference between the recombinant proteins. In the $\mathrm{MeO}-$ AMVN environment both recombinant proteins showed statistically lower MDA production. MDA production with the WT FABP1 was $79.9 \pm 2.7 \%$ $(\mathrm{p}<0.001)$ while the T94A variant was $87.4 \pm 1.7 \%$ $(\mathrm{p}<0.01)$. As in the AAPH environment, there was no statistical difference between recombinant proteins in the AMVN environment.

Figure $8 \mathrm{C}$ shows results from binding of $\alpha-\mathrm{Br}$ PA to WT FABP1 or T94A in the AAPH environment. The WT FABP1 showed a decrease in MDA production to $86.9 \pm 1.9 \%(\mathrm{p}<0.01)$ of control while the T94A variant was $97.3 \pm 1.4 \%$. The T94A was not statistically different from control $(p>0.05)$ but significantly different from the WT FABP1 $(\mathrm{p}<0.05)$. In the MeO-AMVN (lipophilic) environment, both recombinant proteins showed statistically lower MDA production. MDA production with the WT FABP1 was $85.2 \pm 3.8$ $(\mathrm{p}<0.001)$ while the T94A variant was $87.1 \pm 5.5 \%$ $(p<0.05)$. As in the AAPH environment, there was no statistical difference between recombinant proteins in the MeO-AMVN environment.

\section{DISCUSSION}

Oxidative stress has been implicated in the pathogenesis of several liver diseases such as NAFLD $(20,21)$, ALD $(22,23)$, Hepatitis C (24), and NASH $(25,26)$. The excessive amount of prooxidants such ROS and RNS being produced by cells at times overwhelms the body's antioxidant defense systems. FABP1, a small (14 $\mathrm{kDa})$ ubiquitous cytosolic protein could reach concentrations of up to $400 \mu \mathrm{M}$ in murine and $1000 \mu \mathrm{M}$ in human liver (27, 27), has been shown to act as an antioxidant (1). FABP1 contains several methionine groups and a single cysteine that are responsible for the molecular mechanism of the protein's antioxidant capacity (7). Cysteine and methionine both contain sulfur atoms where its electronegativity makes them highly susceptible to oxidation. Not only are these residues easily oxidized they take part in redox cycling reactions that regenerate the residues. Solvent accessible methionine and cysteine residues can be oxidized by ROS into methionine sulfoxide and sulfenic acid/sulfinic acid/sulfonic acid, respectively. These residues are reduced back by methionine sulfoxide reductase (29) and thioredoxin (30). Thus, we investigated the antioxidant potential of FABP1 compared to its T94A mutant. FABP1 also binds LCFA and its peroxides products as well as many other ligands including peroxisome proliferators (31), bile acids (32), heme (33), and endocannabinoids (34). Being capable of functioning as an antioxidant and having the capability to partition fatty acids (free vs proteinbound), FABP1 is considered to be a cytoprotectant (35). Since FABP1 is important in the redox homeostasis of the liver and binding many ligands, the loss of one of these functions through SNP can be detrimental.

The recently discovered human T94A variant is a SNP that occurs in the coding region of the FABP1 gene (11). The FABP1 T94A variant's reported phenotypes can be inconsistent. An example is the BMIs and waist circumferences where it was reported the BMI was lower in carriers of the T94A variant (11) while others found it to be higher (36). Differences in such characteristics may be attributed to the diversity amongst the human population being studied. The T94A mutation has been associated with increased LDL cholesterol (37), hepatic TAG accumulation (38), higher basal plasma TAG levels (11) and NAFLD (36). An explanation for these characteristics was that the T94A variant resulted in a total loss of function (39). Others observed no change in ligand binding specificity or changes in the affinity for binding fibrates (14), steric acid or oleic acid (15) between the wild type and the T94A variant protein. Slight changes were seen in the secondary structure binding affinities between the T94A protein and palmitic or linoleic acid (15) and differences in cholesterol affinity and uptake (16). While research uncovered various differences between FABP1 and its T94A variant, none have explored the antioxidant function of the T94A variant. It is important in determining if the T94A mutation is associated with a loss of function with respect to its ability to act as an antioxidant since the pathogenesis of various diseases are linked to oxidative stress. The impairment of an essential cytoprotectant such as FABP1 can be deleterious to carriers. Therefore, gaining insight on this aspect of the T94A variant is important in developing new approaches for treating diseases. 
The GST affinity tag system previously described (7) was used to purify FABP1 and the T94A variant. An N-terminal infusion linker, sequence of GPLGSIAT, remained when PreScission Protease was used to remove the GST tag. This made the weight of the purified rat FABP1 and T94A variant to be 14968.0 and $14938.0 \mathrm{Da}$, respectively (Figure 4). Weight of purified rat FABP1 in the current study was smaller when compared to results previously described (7) where the total weight was $15275.9 \mathrm{Da}$. The extra mass was attributed to having the cysteine glutathionylated, suggesting the current study's purification protocol did not have a gluthionylated cysteine residue and was available for scavenging ROS. A potential limitation of our study was that MALDI-TOF was not conducted for protein confirmation, however, recombinant proteins were identified by SDSPAGE, western blot, and LC-MS/MS.

The present study showed that the recombinant FABP1 T94A variant scavenged ROS to a similar degree as the WT FABP1, as shown by the decrease in DCF fluorescence intensity (Figure 5). The ability of WT FABP1 to reduce DCF fluorescence is consistent with a previous report (7) despite the lower range of concentrations used in the present study.
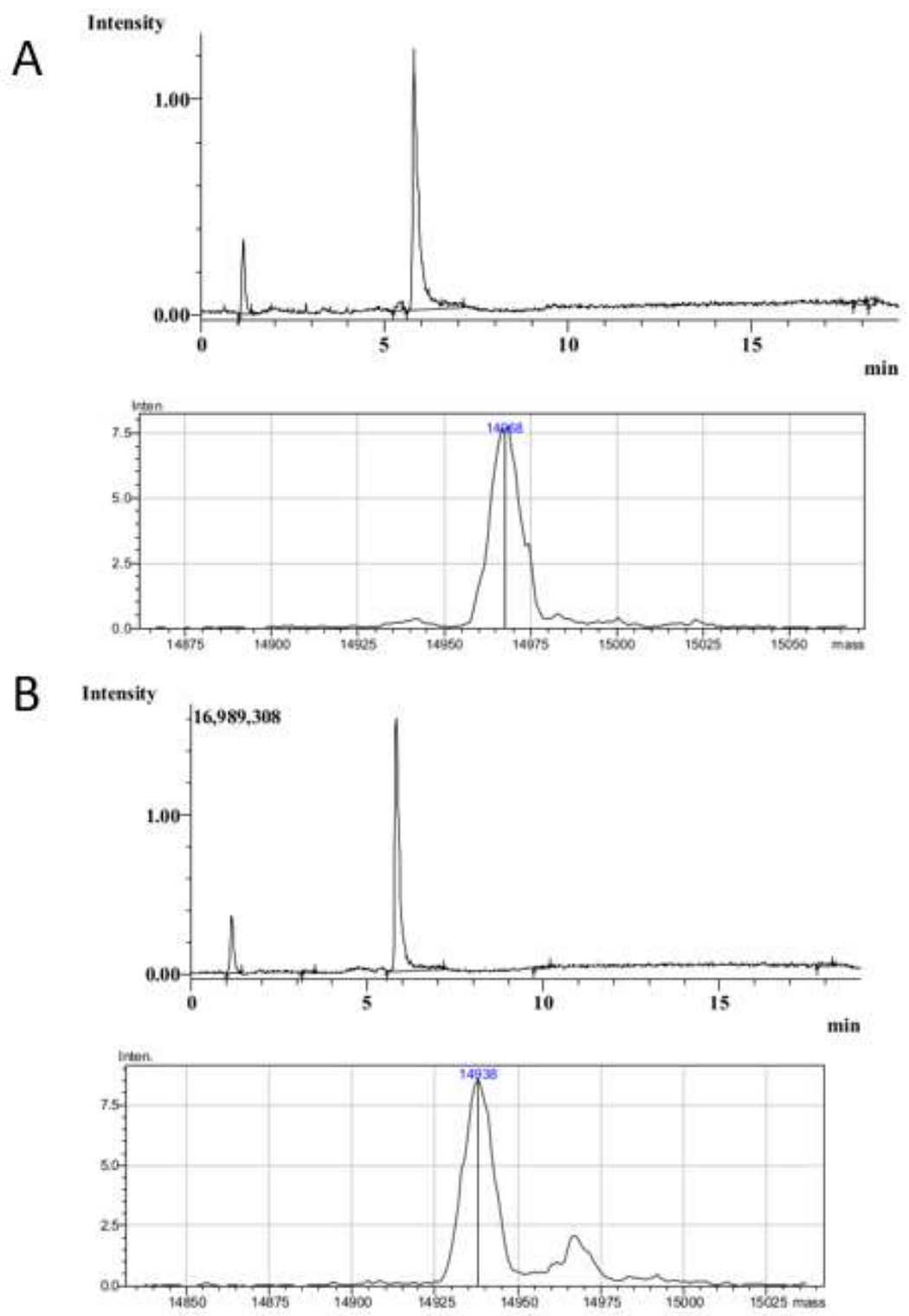

Figure 4. LC-MS Results. Total ion count chromatograms (top) and the deconvoluted mass (bottom) of WT FABP1 (A) and FABP1 T94A mutant (B). Samples were sent to the Pharmaceutical Analysis Laboratory at the College of Pharmacy, University of Manitoba for LC-MS analysis. 


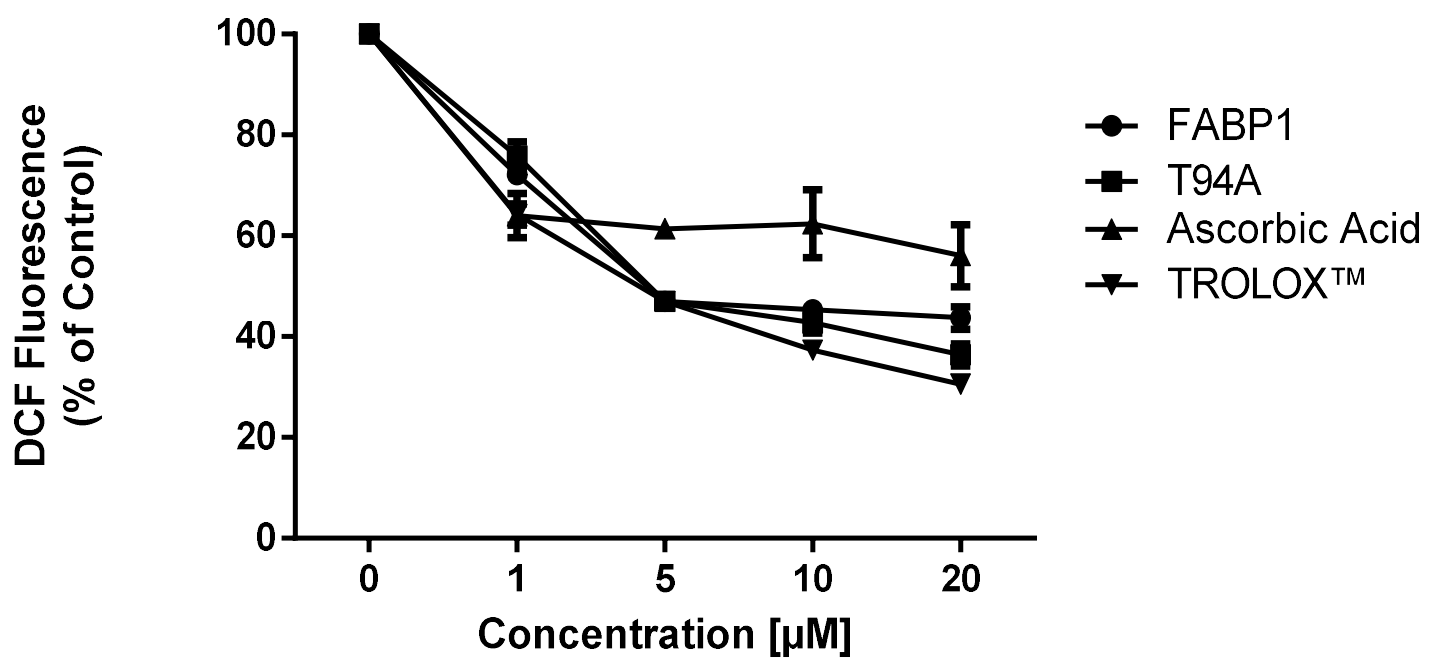

Figure 5. DCF fluorescence intensity versus antioxidants recombinant FABP1, FABP1 T94A, ascorbic acid, and TROLOX ${ }^{\mathrm{TM}}$ concentration. The parent compound DCFH-DA was de-esterified to the dye stock DCFH that was used to detect ROS in the reactions. Reactions were conducted in 96 well CoStar plates with $24 \mu \mathrm{M}$ DCFH, $50 \mu \mathrm{M} \mathrm{FeSO} 4,50 \mu \mathrm{M} \mathrm{H}_{2} \mathrm{O}_{2}$, and protein sample. Data are presented as mean $\pm \operatorname{SEM}(n=4)$. There was a statistical decrease with an increase in protein concentration; $1 \mu \mathrm{M}$ vs $20 \mu \mathrm{M}(\mathrm{p}<0.001)$. Overall, there were no statistical differences between WT FABP1 and T94A in their ability to reduce DCF fluorescence at all concentrations.

To assess the capabilities of the T94A mutant as an antioxidant, the protein was subjected to simulated lipid peroxidation reactions by compounds, AAPH and MeO-AMVN, that thermally decompose into free radicals in hydrophilic and lipophilic environments, respectively. Addition of the T94A protein into these oxidation reactions produced lower amounts of MDA as the concentration of the protein increased (Figure 6). This indicated that the T94A variant can act as both a hydrophilic and lipophilic antioxidant preventing the formation of MDA. Comparing the performance of the mutant variant to the wild type, significant differences were found at $1 \mu \mathrm{M}$ and 10 $\mu \mathrm{M}$ but no differences were seen with $20 \mu \mathrm{M}$ in the AAPH system (Figure 6A). Since FABP1's concentration in human hepatocytes may be as high as $1000 \mu \mathrm{M}(27,28)$ and $200-400 \mu \mathrm{M}$ in rodents (34), the difference between the mutated and nonmutated forms may be considered negligible assuming that at concentrations higher than $20 \mu \mathrm{M}$, the protein behaves similarly in a hydrophilic environment.

When examining proteins in the lipophilic $\mathrm{MeO}-$ AMVN system, there were no significant differences observed (Figure 6B), suggesting that the T94A mutation did not alter protein structure in a way that inhibits the antioxidant moieties from scavenging
ROS in a lipophilic environment. Interestingly, the WT FABP1 protein in the present study did not have a glutathionylated cysteine residue while that in Yan's study it was glutathionylated and hence not available for free radical scavenging. Antioxidant activity, however, was observed to be similar, suggesting that the cysteine residue may not be solvent accessible to scavenge ROS. A study done by Smathers et al., (40) investigating 4hydroxynonenal adduction on FABP1 used in silico simulations and PROPKA (http://propka.ki.ku.dk/) to calculate solvent accessibility. The study illustrated that the apo state of rat FABP1 had its cysteine $11 \%$ buried from the solvent while its holo state was at $37 \%$, suggesting that the cysteine is partially solvent accessible and may not be readily available to scavenge ROS.

WT FABP1's antioxidant function was attenuated when bound with either PA or $\alpha$-Br-PA in both AAPH and MeO-AMVN lipid peroxidation reactions but was still able to significantly decrease MDA production (Figure 8). The T94A variant did not differ significantly compared to control when bound with $\alpha$-Br-PA (Figure 8C) in the hydrophilic milieu. Comparing WT FABP1 to T94A, MDA production showed significant differences in the unbound and bound only with $\alpha-\mathrm{Br}-\mathrm{PA}$ in the AAPH derived lipid peroxiditon system. 


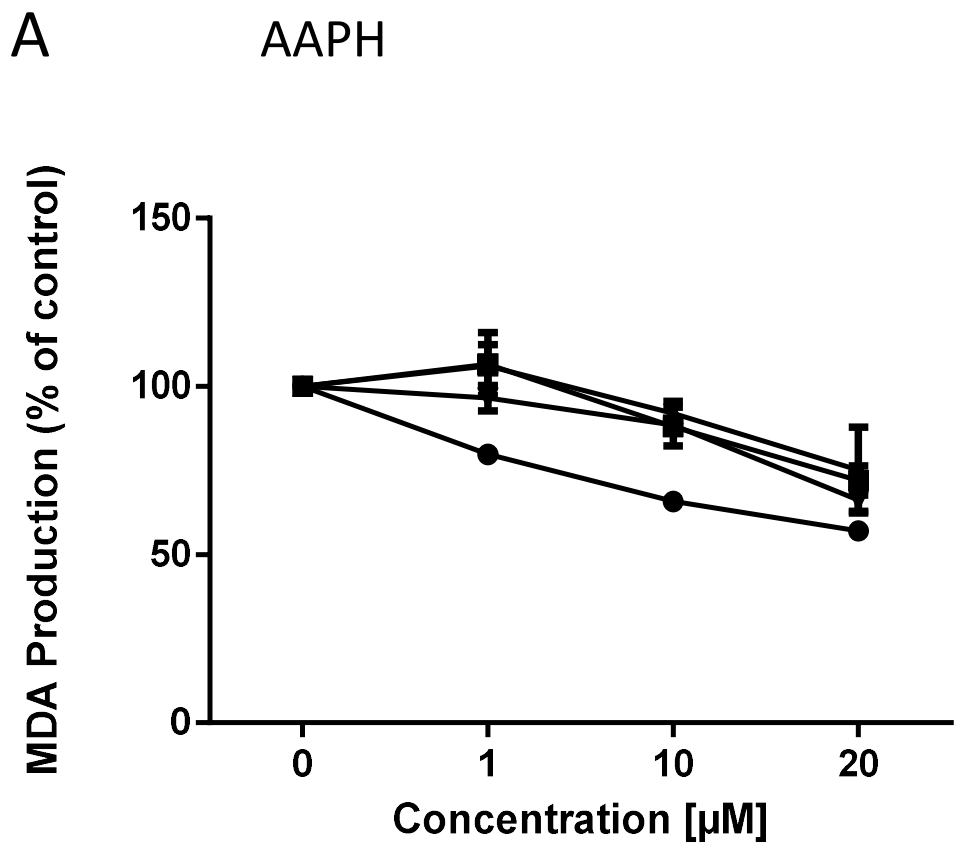

B MeO-AMVN

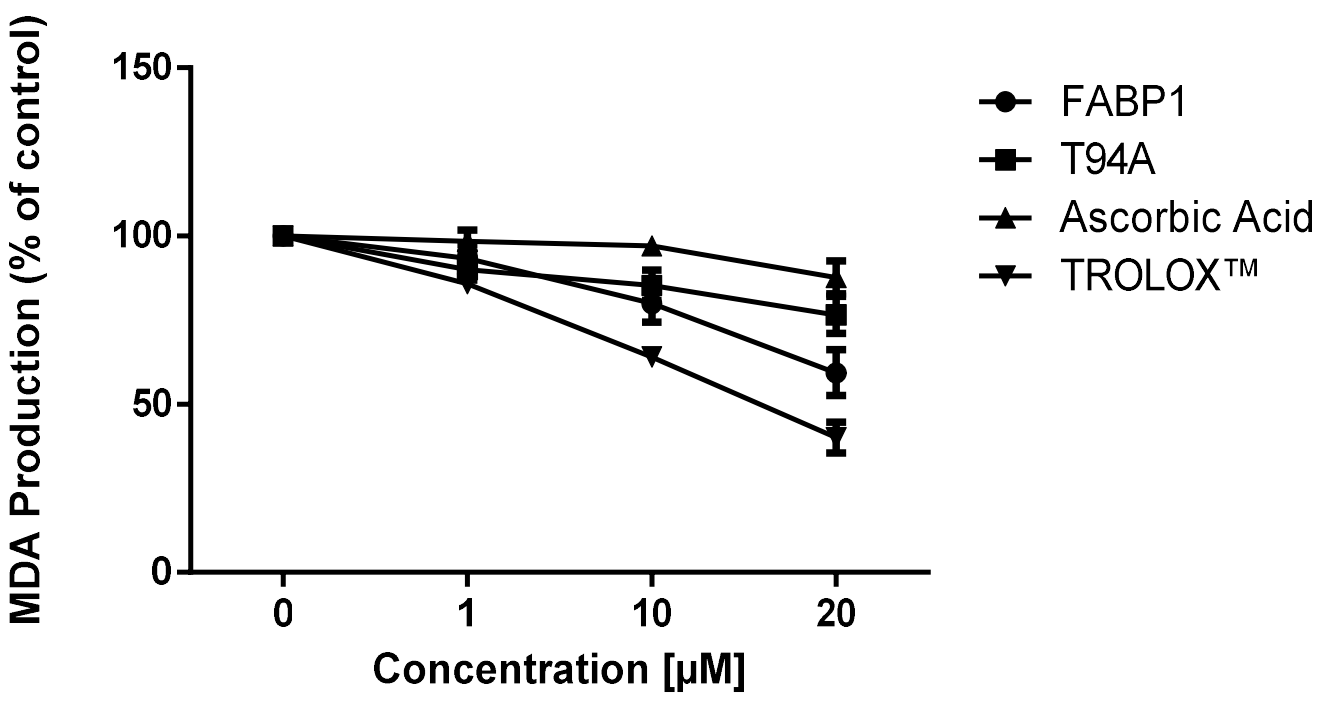

Figure 6. Antioxidants in lipid peroxidation reactions. The effect of WT FABP1, FABP1 T94A mutant, ascorbic acid, and TROLOX $^{\mathrm{TM}}$ on AAPH (hydrophilic) (A) and MeO-AMVN (lipophilic) (B) induced MDA production. LDL was incubated with azo compounds and varying concentrations of WT FABP1, T94A mutant, ascorbic acid, or TROLOX ${ }^{\mathrm{TM}}$ for 90 minutes at $37^{\circ} \mathrm{C}$. MDA was measured using the TBARS assay. Formation of MDA decreased with an increase in protein concentration. There was a statistical difference $(\mathrm{p}<0.05)$ between WT FABP1 and T94A using AAPH induced MDA production at $1 \mu \mathrm{M}(79.8 \% \pm 1.5$ and $105.0 \% \pm 9.4$ of the control) and $10 \mu \mathrm{M}(65.8 \% \pm 1.8$ and $88.1 \% \pm 5.7 \mathrm{of}$ control) $(\mathrm{p}<0.05)$, but not at $20 \mu \mathrm{M}$. WT FABP1 and T94A were not different from each other in the MeO-AMVN system. Values represent mean $\pm \mathrm{SEM}, \mathrm{n}=8$. 

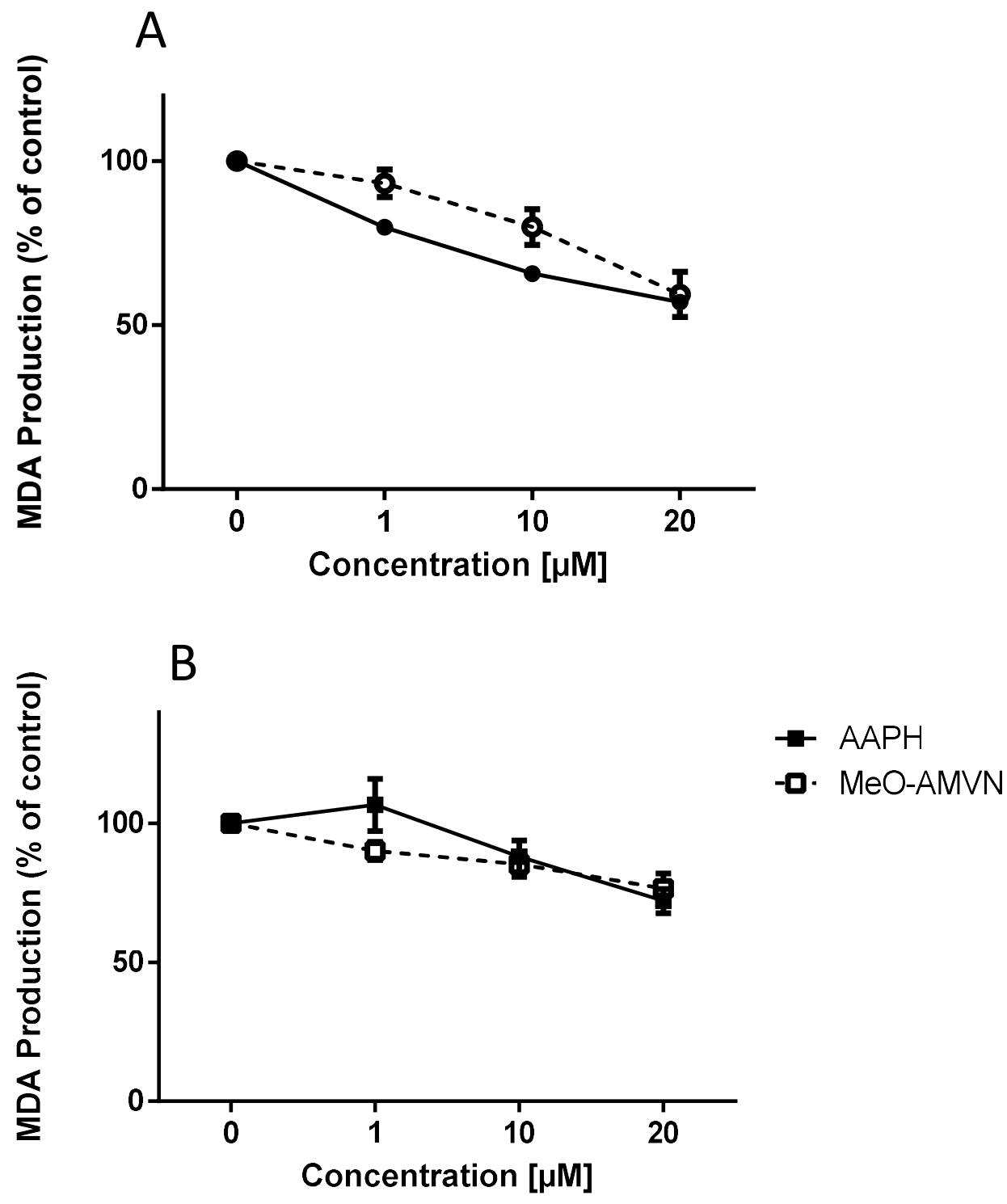

Figure 7. Antioxidant function of WT FABP1 (A) and T94A mutant (B) in hydrophilic and lipophilic environments. FABP1 T94A concentration $(\mu \mathrm{M})$ is shown as a function of MDA production (\% of control) in an AAPH and MeO-AMVN environment. Proteins were able to reduce MDA production similarly despite being induced by different azo compounds. Values represent mean $\pm \mathrm{SEM}, \mathrm{n}=8$.

Results suggest that when the T94A variant binds ligands, the protein's conformation may be unfavourable for scavenging ROS in certain conditions. Some of the antioxidant amino acids of the FABP1 T94A may have become unavailable when ligands are bound. Studies have shown no change in ligand specificity and affinity when the T94A variant binds ligands $(14,15)$, which implies that the mutation does not cause a loss of function.
However, the secondary structural response of the mutant when bound with ligands has been shown to influence the protein's downstream interaction with PPAR $\alpha$ (14). Consistent with these findings, the present study found that although there was no loss in overall antioxidant activity (Figure 5), results seen in Figure 8 imply that ligand binding can influence the T94A variant from WT FABP1 in different environments. 

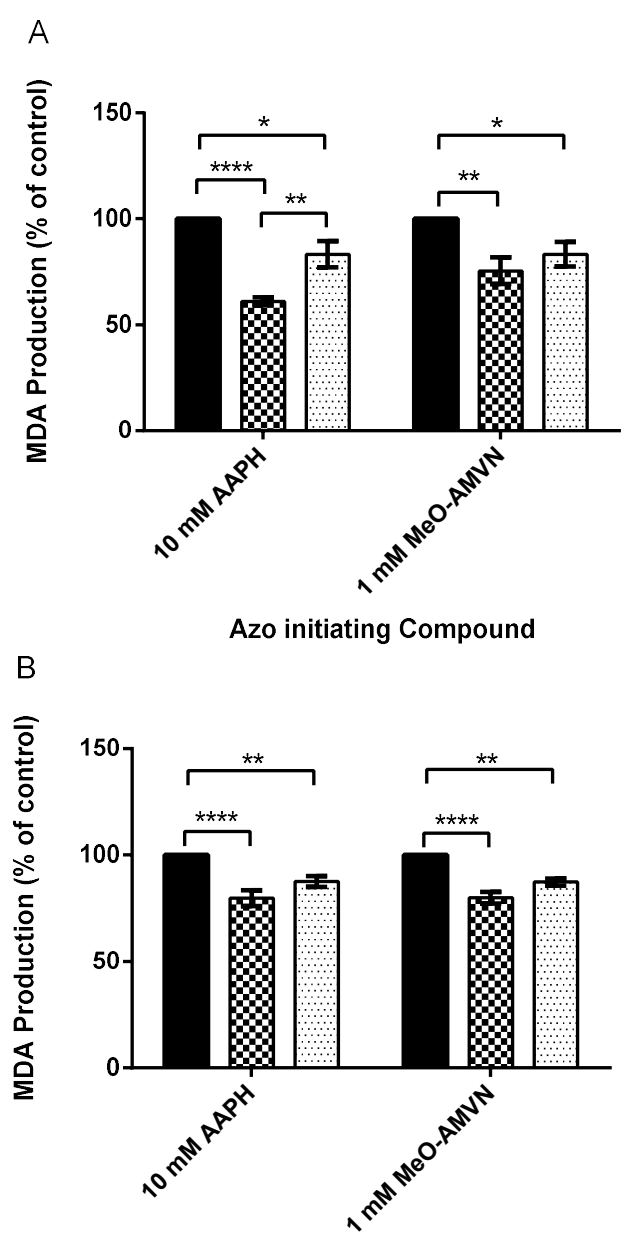

Azo initiating Compound

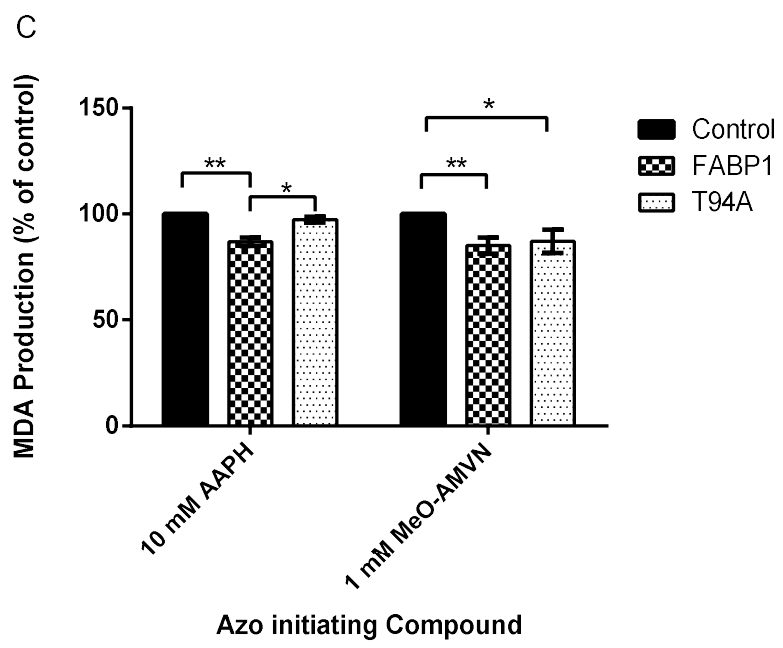

Figure 8. Comparison of the effect of unbound recombinant proteins (A), after binding with PA (B), and after binding with palmitate $\alpha$-Br-PA $(\mathrm{C})$, on azo compounds AAPH and MeO-AMVN free radical release. Recombinant proteins $(10 \mu \mathrm{M})$ were pre-incubated with either no fatty acid (A), PA (B), or $\alpha$-Br-PA (C) for 1 hour at $37^{\circ} \mathrm{C}$ before being used in the lipid peroxidation reactions. MDA levels were measured using the TBARS assay. Control reflect MDA levels produced in lipid peroxidation reactions without WT FABP1 or T94A mutant. Values represent mean $\pm \mathrm{SEM}, \mathrm{n}=6$,

$* \mathrm{p}<0.05, * * \mathrm{p}<0.01, * * * * \mathrm{p}<0.001)$. 
Previously reported, T94A variant has a lower binding affinity with palmitic and linoleic acid (15), which may illustrate that the T94A variant could be more readily available to act as an antioxidant. This was not observed as the antioxidant ability was similar to the WT when it was unbound and bound with $\alpha$-Br-PA in the AAPH lipid peroxidation system. The secondary structural changes in response to LCFAs binding with the T94A variant is a possible reason for the weakened antioxidant response. While FABP 1 is found to a lesser extent in other tissues (41) and presumed to have similar roles, example kidney (42), it is acknowledged that these studies were conducted with low protein concentrations. It may be that our results could be extended to higher protein concentrations but this needs verification. We also recognize that the use of recombinant rat instead of human FABP1 may be considered a limitation to our study, as the latter would have shown clinically relevance.

\section{CONCLUSION}

In the current study, recombinant rat FABP1 T94A variant was purified using the GST tag system and in vitro studies were used in determining the mutant protein's antioxidant activity. From these results, recombinant rat FABP1 T94A variant was shown to also act as an antioxidant similar to FABP1 and can do so in hydrophilic and lipophilic environments. There were no significant differences between the performance of the wild type and mutant, suggesting that the T94A substitution does not impact the protein's antioxidant function. However, it was found that when T94A was bound to $\alpha$-Br-PA, the T94A protein was unable to significantly reduce the generation of MDA in a hydrophilic millieu, which may suggest there is an altered antioxidant function once ligands bind to the protein. Further studies using higher protein concentrations and larger $n$ values will help verify these results.

\section{REFERENCES}

1. Haunerland N, Spener F. Fatty acid-binding proteins - insights from genetic manipulations. Prog Lipid Res. 2004;43(4):328-49.

2. Wang G, Gong Y, Anderson J, Sun D, Minuk G, Roberts M, et al. Antioxidative function of L-FABP in L-FABP stably transfected Chang liver cells. Hepatology. 2005;42(4):871-9.

3. Rajaraman G, Wang G, Yan J, Jiang P, Gong Y, Burczynski F. Role of cytosolic liver fatty acid binding protein in hepatocellular oxidative stress: effect of dexamethasone and clofibrate treatment. Mol Cell Biochem. 2007;295(1-2):27-34.

4. Wang G, Shen H, Rajaraman G, Roberts M, Gong Y, Jiang $\mathrm{P}$, et al. Expression and antioxidant function of liver fatty acid binding protein in normal and bileduct ligated rats. Eur J Pharmacol. 2007;560(1):61-8.

5. Smathers R, Galligan J, Shearn C, Fritz K, Mercer K, Ronis M, et al. Susceptibility of L-FABP-/- mice to oxidative stress in early-stage alcoholic liver. J Lipid Res. 2013;54(5):1335-45.

6. Gong Y, Wang G, Gong Y, Yan J, Chen Y, Burczynski F. Hepatoprotective role of liver fatty acid binding protein in acetaminophen induced toxicity. Bmc Gastroenterol. 2014;14(1):1-7

7. Chen Y, Li W, Yuewen G, Guqi W, Frank B. Clofibrate Attenuates ROS Production by Lipid Overload in Cultured Rat Hepatoma Cells. J Pharm Pharm Sci. 2017;20:239-51.

8. Yan J, Gong Y, She Y-M, Wang G, Roberts MS, Burczynski FJ. Molecular mechanism of recombinant liver fatty acid binding protein's antioxidant activity. Journal of Lipid Research. 2009;50(12):2445-54.

9. Qi Z, Liu Y, Wang W, Xin Y, Xie F, Wang A-L. Fatty acid binding protein 10 in the orange-spotted grouper (Epinephelus coioides): Characterization and regulation under $\mathrm{pH}$ and temperature stress. Comp Biochem Physiology Part C Toxicol Pharmacol. 2012;155(3):447-55.

10. Zhang Y, Liu K, Hassan H, Guo H, Ding P, Han L, et al. L-FABP-deficiency provoked oxidative stress, inflammation and apoptosis-mediated hepatotoxicity induced by pyrazinamide on zebrafish larvae. Antimicrob Agents Ch. 2016;AAC.01693-16.

11. Brouillette C, Bossé Y, Pérusse L, Gaudet D, Vohl M-C. Effect of liver fatty acid binding protein (FABP) T94A missense mutation on plasma lipoprotein responsiveness to treatment with fenofibrate. Journal of Human Genetics. $0 ; 49(8): 424-32$.

12. Robitaille J, Brouillette C, Lemieux S, Pérusse L, Gaudet D, Vohl M. Plasma concentrations of apolipoprotein B are modulated by a gene-diet interaction effect between the LFABP T94A polymorphism and dietary fat intake in FrenchCanadian men. Molecular Genetics and Metabolism. 2004;82(4):296-303.

13. Yamada Y, Kato K, Oguri M, Yoshida T, Yokoi K, Watanabe S, et al. Association of genetic variants with atherothrombotic cerebral infarction in Japanese individuals with metabolic syndrome. Int J Mol Med. 2008 Jun;21(6):801-8.

14. Tian Y, Li H, Wang S, Yan J, Chen Z, Li Z, et al. Association of L-FABP T94A and MTP I128T polymorphisms with hyperlipidemia in Chinese subjects. Lipids. 2015;50(3):275-82. 
15. Martin G, McIntosh A, Huang H, Gupta S, Atshaves B, Landrock K, et al. The Human Liver Fatty Acid Binding Protein T94A Variant Alters the Structure, Stability, and Interaction with Fibrates. Biochemistry. 2013;52(51):9347-57.

16. Huang H, L M Avery, Martin GG, Landrock KK, Landrock D, Gupta S, et al. Structural and functional interaction of fatty acids with human liver fatty acidbinding protein (L-FABP) T94A variant. The FEBS journal. 2014;281(9):2266-83.

17. Huang H, L M Avery, Landrock KK, Landrock D, Storey SM, Martin GG, et al. Human FABP1 T94A variant enhances cholesterol uptake. Biochimica Et Biophysica Acta. 2015;1851(7):946-55.

18. Bass, N. M., Manning, J. A., Ockner, R. K., Gordon, J. I., Seetharam, S., and Alpers, D. H. (1985) Regulation of the biosynthesis of two distinct fatty acid-binding proteins in rat liver and intestine. Influences of sex difference and of clofibrate. J. Biol. Chem. 260, 1432-1436

19. Trehan A, Kiełbus M, Czapinski J, Stepulak A, Huhtaniemi I, Adolfo R-M. REPLACR-mutagenesis, a one-step method for site-directed mutagenesis by recombineering. Sci Rep-uk. 2016;6(1):19121.

20. Carter P. Site-directed mutagenesis. Biochem J. 1986;237(1):1-7.Minicis S, Brenner D. Oxidative stress in alcoholic liver disease: Role of NADPH oxidase complex. J Gastroen Hepatol. 2008;23(s1):S98-103.

21. Sumida $Y$, Niki E, Naito $Y$, Yoshikawa $T$. Involvement of free radicals and oxidative stress in NAFLD/NASH. Free Radical Res. 2013;47(11):86980.

22. Polimeni L. Oxidative stress: New insights on the association of non-alcoholic fatty liver disease and atherosclerosis. World J Hepatology. 2015;7(10):1325.

23. Cederbaum AI, Lu Y, Wu D. Role of oxidative stress in alcohol-induced liver injury. Arch Toxicol. 2009;83(6):519-48.

24. Sid B, Verrax J, Calderon P. Role of oxidative stress in the pathogenesis of alcohol-induced liver disease. Free Radical Res. 2013;47(11):894-904.

25. Koike K. Pathogenesis of HCV-associated HCC: Dual-pass carcinogenesis through activation of oxidative stress and intracellular signaling. Hepatol Res. 2007;37(s2):S115-20.

26. Morris E, Fletcher J, Thyfault J, Rector R. The role of angiotensin II in nonalcoholic steatohepatitis. Mol Cell Endocrinol. 2013;378(1-2):29-40.

27. Sutti S, Jindal A, Locatelli I, Vacchiano M, Gigliotti $\mathrm{L}$, Bozzola $\mathrm{C}$, et al. Adaptive immune responses triggered by oxidative stress contribute to hepatic inflammation in NASH. Hepatology. 2014;59(3):886-97.

28. McArthur MJ, Atshaves BP, Frolov A, Foxworth WD, Kier AB, Schroeder F. Cellular uptake and intracellular trafficking of long chain fatty acids. J Lipid Res. 1999 Aug;40(8):1371-83.

29. Favretto F, Assfalg M, Gallo M, Cicero D, Mariapina $\mathrm{D}$, Molinari H. Ligand Binding Promiscuity of Human Liver Fatty Acid Binding Protein: Structural and Dynamic Insights from an Interaction Study with Glycocholate and Oleate. Chembiochem. 2013;14(14):1807-19.

30. Levine RL, Mosoni L, Berlett BS, Stadtman ER. Methionine residues as endogenous antioxidants in proteins. Proc National Acad Sci. 1996;93(26):15036-40.

31. Jan Y-H, Heck DE, Dragomir A-C, Gardner C, Laskin D, Laskin J. Acetaminophen Reactive Intermediates Target Hepatic Thioredoxin Reductase. Chem Res Toxicol. 2014;27(5):882-94.

32. Wolfrum C, Börchers T, Sacchettini J, Spener F. Binding of Fatty Acids and Peroxisome Proliferators to Orthologous Fatty Acid Binding Proteins from Human, Murine, and Bovine Liver†. Biochemistryus. $2000 ; 39(6): 1469-74$.

33. Favretto F, Santambrogio C, Mariapina D, Molinari $\mathrm{H}$, Grandori R, Assfalg M. Bile salt recognition by human liver fatty acid binding protein. Febs J. 2015;282(7):1271-88.

34. Stewart J, Slysz G, Pritting M, U M-E. Ferriheme and ferroheme are isosteric inhibitors of fatty acid binding to rat liver fatty acid binding protein. Biochem Cell Biol. 1996;74(2):249-55.

35. Schroeder F, L M Avery, Martin GG, Huang H, Landrock D, Chung S, et al. Fatty Acid Binding Protein-1 (FABP1) and the Human FABP1 T94A Variant: Roles in the Endocannabinoid System and Dyslipidemias. Lipids. 2016;51(6):655-76.

36. Wang G, Bonkovsky HL, de Lemos A, Burczynski FJ. Recent insights into the biological functions of liver fatty acid binding protein 1 . Journal of Lipid Research. 2015;56(12):2238-47.

37. Peng X-E, Wu Y-L, Lu Q-Q, Hu Z-J, Lin X. Two genetic variants in FABP1 and susceptibility to nonalcohol fatty liver disease in a Chinese population. Gene. 2012;500(1):54-8.

38. Fisher E, Weikert C, Klapper M, Lindner I, Möhlig $\mathrm{M}$, Spranger J, et al. L-FABP T94A is associated with fasting triglycerides and LDL-cholesterol in women. Molecular Genetics and Metabolism. 2007;91(3):278-84.

39. McIntosh A, Huang H, Storey S, Landrock K, Landrock D, Petrescu A, et al. Human FABP1 T94A variant impacts fatty acid metabolism and PPAR- $\alpha$ activation in cultured human female hepatocytes. Am J Physiol-gastr L. 2014;307(2):G164-G176.

40. Gao N, Qu X, Yan J, Huang Q, Yuan H-Y, Ouyang D-S. L-FABP T94A decreased fatty acid uptake and altered hepatic triglyceride and cholesterol accumulation in Chang liver cells stably transfected 
with L-FABP. Mol Cell Biochem. springer; 2010;345(1-2):207-14.

41. Smathers R, Fritz K, Galligan J, Shearn C, Reigan P, Marks M, et al. Characterization of 4-HNE Modified L-FABP Reveals Alterations in Structural and Functional Dynamics. Plos One. plos; 2012;7(6):e38459.

42. Antonenkov VD, Sormunen RT, Ohlmeier S, Amery L, Fransen M, Mannaerts GP, et al. Localization of a portion of the liver isoform of fatty-acid-binding protein (L-FABP) to peroxisomes. Biochem J. 2006;394(2):475-84.

43. Kamijo-Ikemori A, Sugaya T, Kimura K. Urinary fatty acid binding protein in renal disease. Clin Chim Acta. 2006;374(1-2):1-7. 